\title{
Formation: Social Representations of Higher Education Teachers in México
}

\author{
Elí Orlando Lozano González \\ National Autonomous University of Mexico, Mexico
}

\begin{abstract}
The objective of this paper is to analyse the social representations of the concept "formation". Two sources of information are taken. First, papers dealing with the subject of teacher formation published in the proceedings of an important Congress on Educational Research held in Mexico in 2017, here we analyse the use and treatment given to the concept of "formation" in documents published in a specialized medium. Second, we applied a mixed questionnaire to 84 teachers from Teacher Training Schools in Mexico and 73 teachers from the National Autonomous University of Mexico. The questionnaire includes a semantic network and open questions that help capturing the Social Representations of these teachers regarding formation. The results show that in the current use of the concept of formation, its limits are blurred and mixed with other similar, but not the same, concepts: education, training, updating, professionalization, schooling, among others. There is a naive and without rigor use of this concept. But above all, the idea that formation can be given and that it is limited to what can be certified predominates, leaving aside its reflexive dimension. This could lead to mechanized formation processes that are far from the original meaning of the concept.
\end{abstract}

\section{Introduction}

This paper is the result of work on the research project "PAPIIT IN406019: Theories, problems and experiences around the formation of higher education teachers" with funding from the General Directorate of Academic Personnel Affairs (DGAPA) of the National Autonomous University of Mexico (UNAM). As part of the actions that we have undertaken among the members of the project is the reading and analysis of various works that deal with the subject of human formation in general, and teacher formation in particular. We have worked with classic authors such as Hegel [1] and Gadamer [2], who discuss about human formation from a philosophical position located in the tradition of romanticism; we also reviewed the contributions of Honoré [3], who proposes a theory about formation. The previous authors are taken up by others in contexts closer to ours, both geographically and temporarily, for example Yurén [4] and Horlacher
[5]. All these authors speak of human formation in general, but they begin to approach the specific issue of teacher formation, in this sense we reviewed Ferry [6], Pérez Gómez [7] and Lozano-Andrade [8].

With the reading of these authors we realized the complexity within the concept of formation, a polysemic concept and without exact definition (as it happens with most of the concepts used in and emerged from the social sciences and humanities), however it raises certain conditions and precisions. We also realized that it is a very popular word, not only in academic specialist circles, but in any setting.

In Mexico, we have noticed an indiscriminate use of the word formation and therefore its content is lost and its limits are blurred with other concepts. For this reason, we included a line of research within the project "Theories, problems and experiences around the formation of higher education teachers" entitled: Social Representations regarding formation in higher education institutions. We investigated around the ideas, attitudes, opinions and beliefs that are held in universities and teacher-training schools of Mexico City regarding formation. For this purpose, we used the theory of Social Representations (SR in forward), a proposal by Moscovici [9] that provides tools to analyse how certain concepts that originally arise from scientific disciplines are gradually integrated into the daily life of societies, and become part of common sense knowledge, fundamental to the support of daily life, but lacking the precision of specialized knowledge.

We have the assumption that the concept of formation is going through a process of re-meaning in the language of everyday life; process in which it gradually loses its limits and its precision. This, we consider, is normal in everyday life, since the knowledge that predominates here is common sense, the SR. But, after reviewing various publications that deal with the subject of higher education teacher formation (since it is the central theme of our project) we realized that something very similar was happening.

We took on the task of searching and analysing articles published in indexed journals dealing with the formation of higher education teachers. We found that the predominant position is to understand formation as equivalent or synonymous of training or schooling; Thus, when speaking about teacher 
training or formation, pedagogical training or didactic training; this is equivalent to saying that certain teachers have taken courses, diplomas or postgraduate courses in the area of education, didactics or pedagogy $[10,11,12,13,14]$.

From a specialized point of view, the concept of "formation" refers to the process of transformation of the individual in relation to otherness, entails the thoughtful thinking and individual consciousness of those who are assumed in formation [1, 2, 3]. This largely transcends the processes that are described in several of the investigations that we reviewed (processes of schooling or training), however they are called, without greater rigor, formation processes.

We enter here into a linguistic controversy, because in Spanish formation is not, or should not be, the same as training; but in the English language this seems to be the case. In English people talk of teacher training processes as an equivalent for teacher formation. Formation, education and training are very similar concepts, but they are not the same. This research is carried out in Mexico, therefore in Spanish, and it is from this linguistic perspective that we reach the conclusions here presented.

In these pages we analyse the papers that address the issue of teacher formation presented at the National Congress of Educational Research (CNIE) of the Mexican Council for Educational Research (COMIE) held in November 2017 in Mexico. This is a congress where hundreds of papers are presented and it represents the state of educational research issues in Mexico.

Based on the previous analysis, a second stage of this research was to apply a questionnaire among higher education teachers from various educational institutions in Mexico to find out their SR regarding the concept of formation. This document briefly discusses the results in this regard.

\section{Brief approach to the concept of Formation}

It is very difficult to summarize in a few lines what formation is, but we will try to do it in this paper for expository purposes. Hegel [1] and Gadamer [2], mention that formation is the process by which individuals appropriate culture, it is the passage from particularity to generality. In other words, it implies accessing to new knowledge and ways of life and accepting them as your own; it is to overcome one's own nature through the access to culture. With the use reason involved, formation implies the development of tact, prudence and recognition of the other; therefore it goes beyond skills, knowledge and behaviours. These authors also mention that formation is a duty to oneself.

Honoré [3] studies this phenomenon carefully and proposes certain conditions to formation: it requires a progressive knowledge of reality; to get out of the comfort space and face new realities; it happens in the community, in the inter-experience; and it is a process that requires reflexive activity, which implies the transformation of oneself, of our practices, our actions, our meanings, our speech, and thereby we transform the environment, the culture; in the same way, it opposes the reflexive activity to the reflective activity (as it happens in a mirror); the reflective activity equates to the processes of education or training, while the reflexive activity conduces to formation.

Ferry [6] says that formation can only happen as a project of personal transformation: "formation can only be a work on oneself, freely imagined, desired and pursued, carried out through the means offered or that one seeks oneself' (p. 43).

\section{Methodology}

\subsection{Phase one: Analysis of papers}

We consulted the electronic memory of the National Congress of Educational Research (CNIE) organized by the National Council of Educational Research (COMIE) held in November 2017 in the city of San Luis Potosí, Mexico [15]. More than 2000 proposals for papers were sent to this congress in total, of those 1183 were accepted for presentation [16]. For their part, 131 (more than 10\%) were presented in the line of research called "Formation Processes", although not all of them specifically deal with the subject of teacher formation. At this point we applied the first filter, we identified that only 68 of the 131 papers focus on it. These 68 papers are the ones that were carefully analysed for the preparation of this document.

First of all we read each of the 68 rescued papers, in all of them the authors discuss about teacher formation processes at various levels, either as a central or secondary topic. We used the qualitative content analysis strategy proposed by Cáceres [17] to analyse the uses of the concept of formation in each paper. To systematize and organize the analysis, we used a synthesis table with 4 columns: 1) objective of the paper, 2) methodology, 3) main results, 4) concept, notion or idea about "formation".

Once the papers were synthesized and the concept, notion or idea about formation identified, we made a classification of the papers, the results in this document are presented based on that classification.

\subsection{Phase two: Questionnaire}

To know the SR regarding formation of higher education teachers in Mexico, a mixed questionnaire was designed and applied to teachers assigned to various higher education institutions in Mexico. We 
divided the sample into two categories: 1) teachers from Teacher-Training Schools in Mexico City and its Metropolitan Area, since these Higher Education spaces focus on the professional education of future teachers at the basic level; and 2) teachers from UNAM, in particular from the Iztacala Higher Studies School (FESI), which is a school that offers university degrees in the area of health and biology, it is a professionalizing Higher Education space.

Both scenarios are higher level educational spaces, but with different purposes and objectives; one focused on the formation of future teachers (therefore focused on issues of education and formation); and another of health professionals (less closely related to formation topics). Despite their differences, as educational institutions they have teaching as their fundamental task, so the questionnaire was applied among their teachers. There are 84 questionnaires applied to teachers from Teacher-Training Schools (TTS) and 73 at the FESI.

The questionnaire is of a mixed nature, consisting of 5 sections. The first is general data and identification. The second, third and fourth sections are natural semantic networks [18], with three inductor words: Formation, Education and Teaching; here the instruction for the participants are to write 3 words that they associate with the corresponding inductor word, then they are asked to assign a number from one to three according to the importance that each one gives them, finally they are asked to write the reasons why they wrote each of the words they associated with the inductor word. The fifth section consists of three open questions: 1) I define "formation" as... 2) describe in which situations or scenarios of daily life you use the word formation and briefly explain the reasons for it, and 3) at some point in time in your life, have you studied, read or discussed anything about "formation"? Briefly describe your experiences in this regard.

In this paper, the results of these inquiries are presented in a very synthesized way.

\section{Results}

\subsection{Analysis of papers}

Due to space, these pages do not present an exhaustive analysis of the papers found in the CNIE 2017 memories, however, it is possible to present here certain conclusions that we reached from their review and analysis:

- The issue of teacher formation is a current, relevant and problematic topic that requires investigation. This can be affirmed by the simple fact that more than half of the papers that were presented in the line of "formation processes" deal with teacher formation.
- Of the 68 papers analysed, except in 11 of them, there is no discussion or theorizing about what formation is as a concept. It is often used as an umbrella term, a concept in which other concepts fit, but in this mixture the content and limits of each one are diluted. It is used as an equivalent of education, training, updating or professionalization; and the reality is that each of these concepts refers to different processes. The concept of formation is not usually defined in the papers, it is only used.

Figure 1 shows the six classifications obtained from the analysis of the papers and the number of papers included in each one. It is worth mentioning that the same paper could be included in more than one category depending on its content.

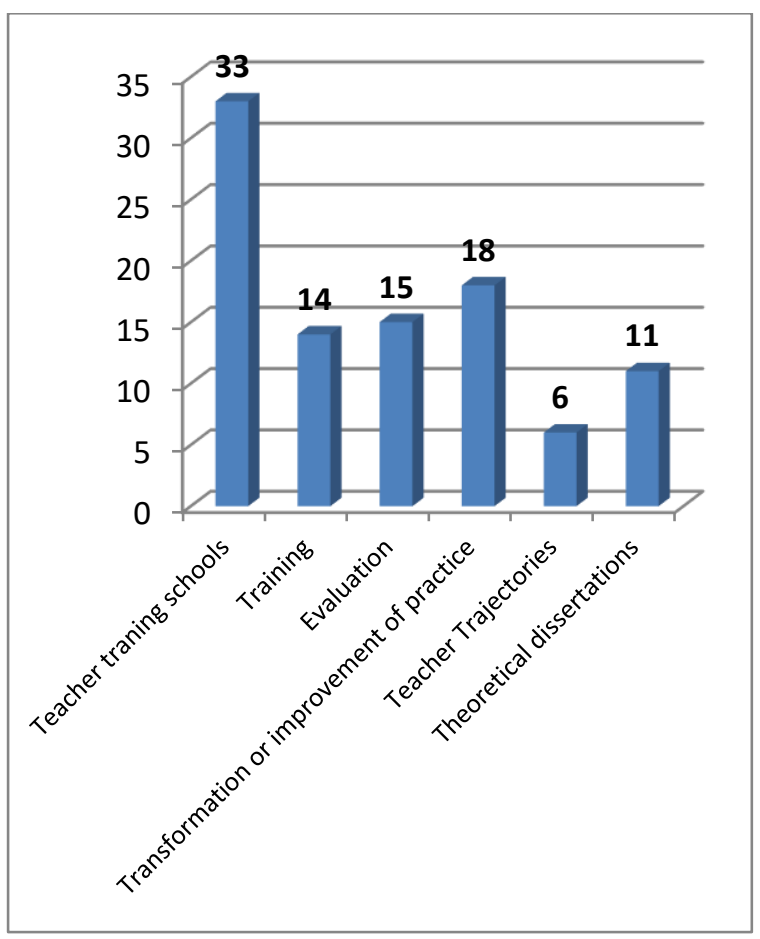

Figure 1. Clasification of papers

At this point, it is necessary to clarify that all the analysed papers are written in Spanish, and in all of them the word formation (formación) is used, alone or in different expressions. Now, in the presentation of this work, it has been decided to translate the Spanish word "formación" as "formation", and not to training (entrenamiento), because we understand that formation and training are different processes and their definition is also different.

Back to the results, in the papers included in the first 5 categories, the word formation frequently appears in different expressions, for example: teacher formation institutions (instituciones formadoras de docentes), initial formation, teacher formation, pedagogical formation of teachers. In these cases, the 
concept of formation is used as equivalent to school education. There is one expression that is frequently used, but is hard to translate to English, it is "teacher educator" (in Spanish formador de docentes, formador de formadores, or docente formador), it refers to a teacher-traning school (Escuela Normal) teacher. Here formation is equivalent to the teaching activity (enseñanza).

Other expressions also appear: formation devices, formation program, formation offer, formation needs, formation system, formation experiences, transfer of pedagogical formation (which refers to the transfer of pedagogical learning), continuous formation devices. In these cases, formation refers to training or updating processes, translated into specific courses or workshops. In all cases, they are processes focused on the modification of behaviour or knowledge through programs directed and planned from the outside. These training processes are expected to directly impact the modification of teaching practice, student learning, or the institutional life of schools.

We consider that training is different to formation because training is defined as the "preparation to acquire or improve the knowledge and skills to carry out a task that professional formation has not provided" [19], and formation goes beyond that.

Formation, in all these cases, is understood as something that can be given and others can receive, as something designed and sent from the outside and that people internalize. Therefore, an externalist and controlled vision of formation predominates.

On the other hand, there are 11 papers located in the category "theoretical dissertations", 6 are theoretical essays on formation and 5 are empirical investigations with strong theoretical support around the same concept. Within the theoretical essays, the concept of formation is linked to some other concepts such as aesthetics, memory, culture, daily life, communicative action, and ethics. In the empirical research papers, the authors analyse phenomena such as: the use of theory in teaching practice, reflection of practice, teacher formation in a rural teacher-training school, development of scientific thinking skills and professionalization of teachers.

In these papers a more rigorous use of the concept is noted, here formation is not compared to other concepts as in the previous categories. A clear relationship between formation and reflexive activity is distinguished, and therefore the idea that formation can be granted or that it comes from outside is abandoned. It is recognized that formation is a personal work, that even transcends school processes and the curriculum.

\subsection{Questionnaire}

First, we present the results of the semantic network of the three inductor words: Formation, Education and Teaching. Only the 10 associated words that make up the core of the network are presented here, those with the highest Semantic Weight (SW). The core of the network was obtained by multiplying the frequency (fr) of each associated word by the Weighted Value (WV), depending on the level of importance that the subjects have given to the words they wrote for each inductor word [17]. The words that make up the core of the network define the content of the SR under study, in this case, the SR about Formation.

These three inductor words (Formation, Education and Teaching) were chosen because we have the assumption that, from common sense thinking, the limits of these concepts are very ambiguous with each other. Furthermore, as we saw in the previous section, the use of the concept of formation is equated with the other two. Two tables are presented below; one is the core of the network of teachers from the UNAM-FESI and the other from the teachers of Teacher-Training Schools.

Table 1. Core of the semantic network (UNAMFESI)

\begin{tabular}{|c|c|c|}
\hline \multicolumn{3}{|c|}{ Formation } \\
\hline Word & $F r$ & $S W$ \\
\hline Education & 18 & 39 \\
\hline Learning & 14 & 32 \\
\hline Studies & 8 & 20 \\
\hline Students & 5 & 14 \\
\hline Development & 8 & 13 \\
\hline Training & 5 & 12 \\
\hline Preparation & 4 & 10 \\
\hline Overcoming & 6 & 10 \\
\hline School & 5 & 9 \\
\hline Academy & 4 & 8 \\
\hline \multicolumn{3}{|c|}{ Education } \\
\hline Word & $F r$ & SW \\
\hline Formation & 10 & 23 \\
\hline Knowledge & 10 & 22 \\
\hline Learning & 12 & 22 \\
\hline Family & 7 & 17 \\
\hline Teacher & 6 & 14 \\
\hline School & 6 & 13 \\
\hline Teaching & 5 & 12 \\
\hline Process & 2 & 6 \\
\hline Work & 2 & 6 \\
\hline Values & 5 & 6 \\
\hline \multicolumn{3}{|c|}{ Teaching } \\
\hline Word & $F r$ & $S W$ \\
\hline Teaching & 19 & 43 \\
\hline Teacher & 9 & 21 \\
\hline Learning & 9 & 18 \\
\hline Commitment & 7 & 16 \\
\hline Formation & 8 & 16 \\
\hline
\end{tabular}




\begin{tabular}{|l|l|l|}
\hline Education & 6 & 15 \\
\hline Knowledge & 6 & 13 \\
\hline Responsibility & 5 & 13 \\
\hline Upgrade & 6 & 12 \\
\hline Student & 6 & 11 \\
\hline
\end{tabular}

Table 2. Core of the semantic network (UNAMFESI)

\begin{tabular}{|c|c|c|}
\hline \multicolumn{3}{|c|}{ Formation } \\
\hline Word & $F r$ & SW \\
\hline Education & 12 & 31 \\
\hline Preparation & 10 & 24 \\
\hline Building & 5 & 18 \\
\hline Development & 8 & 18 \\
\hline Knowledge & 6 & 16 \\
\hline Upgrade & 9 & 14 \\
\hline Learning & 6 & 12 \\
\hline Profession & 5 & 12 \\
\hline Teacher & 6 & 11 \\
\hline School & 4 & 11 \\
\hline \multicolumn{3}{|c|}{ Education } \\
\hline Word & $F r$ & SW \\
\hline Formation & 15 & 29 \\
\hline Learning & 11 & 24 \\
\hline Process & 9 & 23 \\
\hline Values & 10 & 21 \\
\hline Teaching & 7 & 15 \\
\hline Preparation & 8 & 15 \\
\hline Culture & 7 & 14 \\
\hline Knowledge & 6 & 13 \\
\hline School & 7 & 13 \\
\hline Integral & 6 & 12 \\
\hline \multicolumn{3}{|c|}{ Teaching } \\
\hline Word & $F r$ & $S W$ \\
\hline Teaching & 9 & 44 \\
\hline Teacher & 14 & 36 \\
\hline Learning & 8 & 15 \\
\hline Vocation & 5 & 14 \\
\hline Art & 4 & 10 \\
\hline Formation & 4 & 10 \\
\hline Example & 4 & 8 \\
\hline Guide & 4 & 8 \\
\hline Upgrade & 3 & 7 \\
\hline Students & 3 & 7 \\
\hline
\end{tabular}

When reviewing the words that appear in each of the tables it is evident that there are many similarities between the content of the core of the semantic network of each of the inductor words. In fact, the words Education, Formation and Teaching occupy the first places in the two population groups. This shows that, from the SR of higher education teachers, there is no clear distinction between the concepts of Formation, Education and Teaching. We can say this because the responses obtained from the two population groups, thereby the cores of the semantic network in both cases include very similar words.

Strictly speaking, these concepts are not the same, they refer to different things, similar yes, and even related to each other, but ultimately different. According to Fullat "the concepts are defined, they are rigorous. The concept of triangle cannot be confused with that of a circle. The concept has limits, borders, precision, opposition" [20]. What we have here, then, are not concepts, but everyday words whose meanings dilute within each other, whose use refers to very similar processes. They are SR, knowledge that arises from and for everyday life.

Regarding the other sections of the questionnaire, it is worth mentioning that there are few teachers who have studied something about formation, therefore, they cannot be considered specialist; their knowledge arises from everyday life interactions. And the use they give to this word, being teachers, is usually restricted to school settings.

When asked to provide a definition to formation some of the teachers associate it with the performance in professional work, it is considered that formation is the result of a process by which people develop the necessary skills and acquire the knowledge required for adequate performance in the professional work:

Process through which learning is acquired, it allows people to perform better at school or at work (FESIO3).

It is the acquisition of skills and knowledge, for the performance of a profession (TTS22).

I define it as the degree of studies and knowledge possessed by a professional in their field (FESI68).

In this sense, formation is reduced to training, which is an externally directed process in which the objective is the modification of behaviours to achieve certain job performance standards. The following testimonials show that some people who answered the questionnaire understand formation as equivalent to training:

To train someone to be capable of executing the behaviours or goals set (FESI56).

Process by which the human being is traced and addressed (TTS31).

A process in which information is received, behaviours are adopted and thinking is aimed at improving in work and in life (FESI13).

Training is a process that can be given in school settings, and this is a very frequent association when defining formation because some teachers talk about it based on the teacher-student relationship, typical of school education:

An educational process developed by a person called "teacher", who executes a process in which he teaches, and another subject learns knowledge, generally occurring in a school (FESI07).

Process constituted from knowledge between a teacher and a student (TTSO6).

The formation is carried out with the accompaniment of a teacher, who teaches 
content to be learned through formation strategies with teacher intervention. (TTS53)

These testimonies show the close relationship between schooling and formation. They are closely related but are strictly different. Formation, as we have said in these pages, is a personal work, it partially happens in schools, but transcends it. While schooling is strongly associated with education.

In a classical and traditional sense, education could be schematized as the influence of one subject on another for certain purposes. Figure 2 shows this relationship in an extremely simplified manner. The relationship between two individuals is observed, where individual $\mathrm{A}$ influences on the individual $\mathrm{B}$ in an intentionally and planned way, this is, A educates B. This is the typical relation between teacher and student in a school, an educational process.

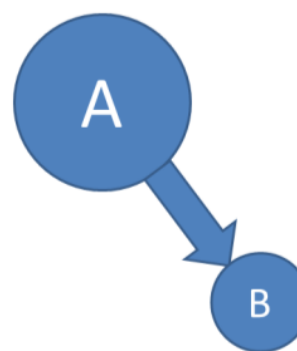

Figure 2. Education

On the other hand, formation, as a personal project, and at the same time is a process of personality formation. It is a project of oneself in which the generality is accepted, rejected, exceeded, or modified; here the subject questions what others do and accept as valid or virtuous. Formation is transformation, therefore there is also a contradiction between what one is and what one wants to be. Hegel states, formation is a duty to oneself. In a simplifying scheme (see Figure 3), the formation would be shown as follows:

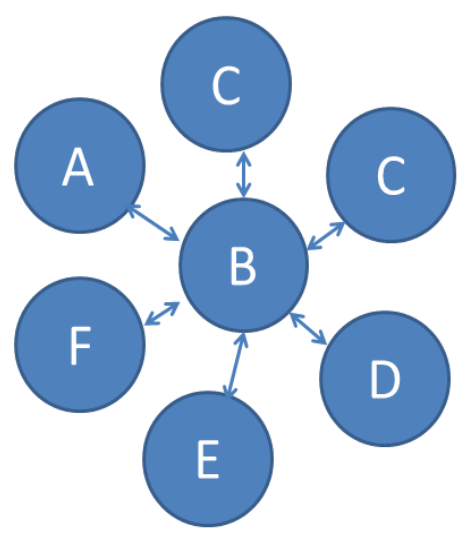

Figure 3. Formation
Here is observed a subject $B$ in the process of formation, through a dialogic process with other subjects, scenarios, and situations (A, C, D, E, F); some of the those educate subject $\mathrm{B}$, but subject $\mathrm{B}$ has a capacity for response and reflexivity where he can accept or reject what is offered from outside himself, and even transform what surrounds him, hence the bidirectional arrows.

This is the definition of formation that we adopt in this paper, but many of the teachers that make up the sample of this study do not recognize it, since they conceive formation as a much simpler and more direct process. However, there are some teachers who wrote definitions that assume formation as an individual process that occurs in cultural settings.

It is a personal process that is built not only with mediators, but also with culture, with others and despite others (EN14).

A process of configuration and construction of oneself, from the events and situations that one lives in different social spaces (EN18).

Although this definition of formation is recognized by some of the teachers who answered the questionnaire, it is not the dominant position. The tendency to think of formation as the act or effect of forming, that is, as an action from outside, predominates. Venegas [21], considers that:

Nowadays, the concept offers a rich scenario to locate formation as a field of meanings in which predominates the action and the effect of forming by the intervention that can be carried out in individuals and where the school becomes one of the legitimized social settings for this purpose (p.24).

However, it is pertinent to distinguish the act of forming (to form) from formation. To form is an expression of daily use that refers to the educability of a person, that is, to the possibility of being educated by others. For its part, the concept of formation, beyond its linguistic similarity to the act of forming, is a different process. Formation includes education, but transcends it, because the subject in process of formation is endowed with a capacity for critical judgment in which he can accept or reject what is offered to him from outside.

It is not surprising that among the population of teachers that were considered in this research, formation is conceived almost as a synonym of education, after all, formation and education can be considered as correlates, since their semantic limits are very close to each other. Nonetheless, as concepts they do not have the same meaning, nor do they refer to the same processes.

\section{Discussion}

In the analysed papers, formation resembles other concepts such as school education, professionalization, updating, training, learning or 
teaching; on many occasions all these terms are used interchangeably. Furthermore, most of the papers did not make a theoretical discussion about the concept, but simply used it, without theoretical-conceptual rigor. On the other hand, the findings of the questionnaire showed a very similar situation. This is understandable in everyday life because it is the terrain where common sense predominates. But the worrying thing is that these uses are also mixed among specialists, people doing pedagogical or educational research.

In most of the analysed publications, it is happening what Bourdieu [22] calls "spontaneous sociology", where preconceived notions, prejudices and the popular use of the concepts predominate: in other words, research is being made from SR. 'Formation' is used without rigor, its limits are blurred; it is equated with other concepts like the previous ones. When formation is equated with training its content is limited. It is reduced to processes of transmission of information and the development to perform specific actions. The results also show that the current use of the word "formation" is associated to processes that occur in school settings. A naive and lack of rigor use of this concept prevails, both in specialized documents and in the daily life of higher education institutions.

This is worrying for educational research, as it shows little rigorous research practices. The analysis reveals that the concept of formation has a popular use, and that its uses are diverse, and this is not necessarily a negative thing. But in this case it is, because 57 of the 68 papers that were analysed here do not discuss the concept, they only use it, as if it was used in any daily conversation: without rigor.

For educational reality this also has implications, since the emancipating, liberating and transforming content of the concept of formation is lost. It is diluted in simpler processes, like training.

It appears that the hegemonic discourse of productivity and consumption had won the battle against critical discourses, such as that of the classical theorists of formation. In the productivity logic, formation is reduced to an object that can be designed, given and received, like any product manufactured in a factory.

We have showed in this paper that the idea that formation can be given and received prevails, thus, it becomes a product, something manufactured, even sold and bought [23]. The predominance of this idea has repercussions, since for educational institutions and for teachers themselves, formation is limited to schooling and training: the certifiable dimension of formation. Leaving aside the personal dimension of formation that refers to personal reflexion and transformation. In this sense, a formed teacher is one who has the certificates that endorse it as such, not one who has thought over his practice to improve and transform it.
We understand that there are various positions to define formation, therefore what is stated in this text should not be considered an absolute and unquestionable truth, but it is clear that the concept of formation is being used indiscriminately. This requires, at the very least, reflection.

Here we do not pretend to give definitions or absolute truths, but rather analysing, problematizing and rescuing the classical notions of formation that today seem to be out of use. And this is important because these notions speak of the transformation of oneself and of one's culture, of leaving individuality and accessing universality, other and better ways of seeing the world; it is a concept that implies accumulation, transformation, criticism, and reflection. Something that is really necessary in this society that has been defined as relativistic, productive-consumerist and liquid [24, 25, 26].

One contribution of this text would be to discuss about the way in which the concept of formation has acquired contents because of the changes in the social, political and economic contexts in which we live, and that has overshadowed the ideas proposed by those who coined the concept. This happens due to the current socio-economic context, defined by globalization, capitalism and consumerism, and a culture of immediacy, where precise and immediate results are sought.

Today's world, beyond the discourses of diversity, multiculturalism, inclusion, and respect, is still a world dominated by the market and the enterprises, which require immediate and effective results to continue producing, so that people continue consuming. This world requires regularity, and this is given by processes such as training and education.

The word formation, in practical and everyday terms, is equivalent to education, teaching, training, instruction, or indoctrination. Processes, mostly unidirectional and that imply, to a greater or lesser extent, the imposition of a reality and the modelling of people according to an ideal designed from the outside. Making people believe (falsely) that their interests are equal to the interest of others.

As formation is a correlate of education, and under the currently dominant idea that education is the solution to the great problems of societies and that it is the trigger for the economic, social, and political development of any country [27], this discussion takes on importance. Because education is not a politically neutral or good act by itself, it is an act that carries intentions, interests. That is why the powerful social classes show interest in these issues.

The issue is aggravated when education/formation is reduced to schooling, and in this scenario the teacher is the main responsible for the success of educational projects. $\mathrm{He}$ is the one who bears the responsibility of "forming" the subjects that today's society needs to get it out of its stagnation and solve its problems. 
Under this panorama, the teacher is a kind of sculptor, who shapes the students according to the desired ideal. And that ideal is none other than the one coming from the market society: efficient workers and consumers.

It is worth closing with some questions: if students are subjects that allow themselves to be formed by their teachers, where is their own will, their desires, their aspirations, their ideals? When students are being formed, do teachers impose their vision of the world on them? And is this their own vision of the world, or is it the one that was formed before by their own "trainers"? Do students have a voice and capacity for action when the idea of "forming" comes from an external perspective incarnated in the figure of the teacher? Doesn't the idea of "forming" contradict the basic principles of the constructivist school, which currently guides the plans and programs of almost any school institution? Isn't the idea of "forming" loaded with a high level of power and even a certain arrogance?

\section{References}

[1] Hegel, G. W. F., Propedéutica filosófica, UNAM, México, 1984.

[2] Gadamer, H. G., Verdad y Método, Sígueme, Salamánca, 2012.

[3] Honoré, B., Para una teoría de la formación: Dinámica de la formatividad. Narcea, Madrid, 1980.

[4] Yurén Camarena, M. T., "Formación, horizonte al quehacer académico (Reflexiones filosóficopedagógicas)”. UPN, México, 1999.

[5] Horlacher, R., Bildung, la formación, Octaedro, Barcelona, 2015.

[6] Ferry, G., El trayecto de la formación: Los enseñantes entre la teoría y la práctica, UNAM - Paidós, México, 1990.

[7] Pérez Gómez, Á., "La función y formación del profesor/a en la enseñanza para la comprensión. Diferentes perspectivas.", in Sacristán, J. G. and Á. Pérez Gómez, Comprender y transformar la enseñanza. Morata, Madrid, 2008.

[8] Lozano Andrade, I., Teoría y práctica en la formación docente. Una mirada sociológica. Newton, México, 2017. [9] Moscovici, S., El psicoanálisis, su imagen y su público. Huemul, Buenos Aires, 1979.

[10] Benito, E., "La formación en psicología: revisión y perspectivas”, Revista Psciencia, 1(2), 2009, pp. 1-12.

[11] Campos, N., "La formación pedagógica de profesores de medicina", Revista Latinoamericana de Enfermagem, 18(1), 2010, pp. 1-7.
[12] López de la Madrid, M. C. and Chávez, J. A., "La formación de profesores universitarios en la aplicación de las TIC". Sinéctica: revista de educación, 41, 2013, pp. 118.

[13] Pinilla, A., "Modelos pedagógicos y formación de profesionales en el área de la salud", Acta médica colombiana, 36(4), 2011, pp. 204-218.

[14] Sánchez, M. y Mayor, C., "Los jóvenes profesores universitarios y su formación pedagógica", Revista de Educación, 339(2006), 2006, pp. 923-946.

[15] Consejo Mexicano de Investigación EducativaCOMIE, Memoria electrónica del Congreso Nacional de Investigación Educativa. San Luis Potosí: COMIE, 2017, http://www.comie.org.mx/congreso/memoriaelectronica/v1 4/index.htm (Access date: 6 November 2020).

[16] Rodríguez Gómez-Guerra, R., COMIE: El congreso invisible, 2018,http://www.comie.org.mx/v5/sitio/2018/07/ 06/congreso_invisible/ (Access date: 6 November 2020).

[17] Cáceres, P., “Análisis cualitativo de contenido: Una alternativa metodológica alcanzable". Psicoperspectivas, II, 2003, pp. 53-82.

[18] Reyes Lagunes, I., "Las redes semánticas naturales, su conceptualización y su utilización en la construcción de instrumentos", Revista de Psicología Social y Personalidad, IX(1),1993, pp. 81-97.

[19] Ander-egg, E., Diccionario de pedagogía, Magisterio del Río de la Plata, Buenos Aires, 1999. p. 46.

[20] Fullat, O., "Prólogo", in Ponce Rivas, A. Columnas metodológicas o Sócrates nada sabe acerca de Zeus, INAD, México, 1996. p. 15.

[21] Venegas Renauld, M. E., "El concepto pedagógico 'Formación' en el universo semántico de la educación", Revista Educación. 28(2), 2008, pp. 13-28.

[22] Bourdieu, P., El oficio del sociólogo, Siglo XXI, México, 2008.

[23] Lozano González, E. O., "Teacher formation and teaching culture in everyday school life at university: the area of health case", The international journal of humanities education. 16(1-2), 2018, pp. 33-43.

[24] Bauman, Z., La cultura en el mundo de la modernidad líquida, Fondo de Cultura Económica, México, 2013.

[25]Hargreaves, A., Profesorado, cultura y posmodernidad: cambian los tiempos, cambia el profesorado, Morata, Madrid, 2005.

[26] Lipovetsky, G. La era del vacío, Anagrama, Barcelona, 2005

[27] Delors, J., La educación encierra un tesoro, UNESCO, París, 1998. 